\title{
Cálculo de reflectancia en imágenes Landsat OLI-8, sobre la región central de Honduras, mediante software libre SEXTANTE.
}

Rafael Enrique Corrales Andino

Vilma Lorena Ochoa López

\section{Resumen}

En esta investigación se elaboró un modelo para la corrección de imágenes con valores de ND (Números Digitales) a parámetros físicos como Reflectancia Satelital, lo que permite reducir errores provocados por efectos atmosféricos. Se utilizó como medio de trabajo para el Modelamiento de algoritmos, el Programa de uso libre SEXTANTE, que corre en la plataforma de gvSIG. La metodología aplicada fue el cálculo de magnitudes físicas para la conversión a reflectancia a tope de atmósfera (TOA) con corrección angular. El modelo generado servirá para la calibración de Imágenes Satelitales del programa LandSat sensor Operational Land Imager (OLI), y de esta manera reforzar el análisis de Teledetección aplicada. Como estrategia de validación del modelo generado, se comprobó su funcionalidad en un trabajo de investigación de tesis en el posgrado de Maestría en Ordenamiento y Gestión del Territorio de la Facultad de Ciencias Espaciales, bajo el tema: Análisis Multitemporal de la Cobertura de la Tierra de la Subcuenca del Río Mocal, Lempira, Honduras, durante el Período de los años 1988 al 2014. El principal resultado fue la arquitectura completa del modelo que calcula la radiometría a partir de la información del metadato de las imágenes LandSat 8 (OLI).

Palabras Clave: Reflectancia, LandSat OLI, SEXTANTE, gvSIG, Honduras.

\section{Abstract}

In this research a model for image correction values from ND (Digital Numbers) to physical parameters such as Satellite Reflectance was developed, which reduces errors caused by atmospheric effects. It was used as a working environment for the modeling of algorithms, the free use SEXTANTE Program, which runs on the platform of gVSIG. The methodology used was the calculation of physical quantities for conversion to Top of Atmosphere reflectance (TOA) with angular correction. The 
model generated serve for calibration of Landsat Satellite Program Operational Land Imager sensor (OLI), and thus strengthen the analysis of remote sensing applied. As validation strategy generated model, its functionality was verified in a research thesis in the postgraduate Master of Planning and Land Management Faculty of Spatial Sciences, under the theme: Multi- Analysis Coverage Earth subwatershed River Mocal, Lempira, Honduras, during the period from 1988 to 2014. The main result was the complete architecture model that calculates the radiometric information from the metadata of Landsat 8 images (OLI).

Keywords: Reflectance, LandSat OLI, SEXTANTE, gvSIG, Honduras.

Rafael Enrique Corrales Andino (Corrales.rafael@gmail.com), Vilma Lorena Ochoa López, Departamento de Ciencia y Tecnologías de la Información Geográfica, Facultad de Ciencias Espaciales, UNAH. 


\section{INTRODUCCIÓN}

Uno de los requisitos indispensables para la puesta en marcha de cualquier proyecto de Percepción Remota (Teledetección Espacial), es la aplicación de correcciones geométricas y radiométricas, en condiciones óptimas calibradas con parámetros superficiales tomados insitu con radio espectrómetros, las que se traducen en firmas espectrales que caracterizan las diferentes coberturas del suelo y su interacción con la energía capturada por el sensor.

Para estos efectos Teledetección es el vocablo derivado del inglés Remote Sensing, para designar a cualquier medio de observación remota, que involucra los procesos de adquisición de las imágenes digitales y su posterior tratamiento (Chuvieco, 2002). También es definida como una técnica de carácter multidisciplinario que permite adquirir imágenes de la superficie terrestre desde sensores instalados en plataformas espaciales, mediando un mecanismo de transporte de energía electromagnética, natural o artificial (Hernández y García, 2014).

Una Imagen Digital, según Pinilla (1995 citado por Corrales, 2010), es una función discretizada de la imagen analógica, en las dimensiones geométricas, por la generación de celdas por muestreo equiespaciado de la superficie (Figura 1), como en sentido radiométrico, por la asignación de valores enteros o Niveles Digitales (ND), que están comprendidos entre 0 y k1, siendo k el margen dinámico del sistema, determinado a su vez por su resolución radiométrica.
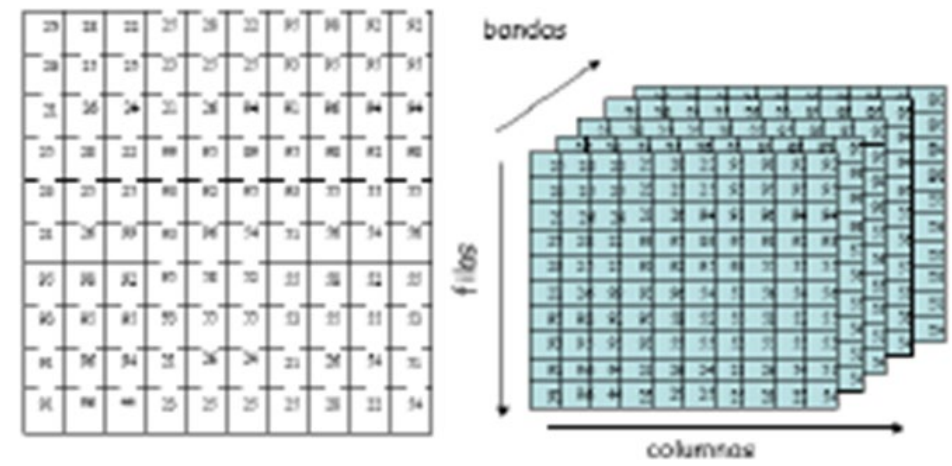

Figura 1. Estructura de una imagen digital (Corrales, 2010).

El Programa LANDSAT: (Land=tierra y Sat=satélite) fue el primer satélite enviado por los Estados Unidos para el monitoreo de los recursos terrestres. Inicialmente se 
le denomino ERTS-1 (EarthResourcesTecnologySatellite) y a partir de 1975 recibe el nombre de LANDSAT. La constelación LANDSAT está formada por 7 satélites que provenían, tanto conceptual como estructuralmente, de los satélites para fines meteorológicos Nimbus. Llevaron a bordo diferentes instrumentos, siempre con la filosofía de captar mayor información de la superficie terrestre, con mayor precisión y a mayor detalle, de ahí sus mejoras radiométricas, geométricas y espaciales (INEGI, s.a., Chuvieco, 2002).

El sensor TM (LandSat TM o ThematicMapper), es un radiómetro multiespectral, diseñado para la cartografía temática e incorporado en los sensores LandSat a partir del lanzamiento del LandSat 4 y 5 . Este sensor está compuesto por 7 bandas espectrales, que incluyen las del espectro visible, las bandas del infrarrojo cercano y medio, y la banda del infrarrojo térmico.

LandSatETM+ o EnchancementThematicMapper Plus es el radiometromultispectral, que mejora las características del sensor TM, agregando una octava banda, la Pancromatica, de $15 \mathrm{~m}$ de resolución, y mejorando la resolución de la banda térmica aumentando su resolución espacial a $60 \mathrm{~m}$.

LandSatOLI (OperationalLandlmager), este es uno de los dos sensores de la octava versión del programa LandSat. Las bandas espectrales del sensor OLI, aunque similares al sensor Landsat $7 \mathrm{ETM}+$, proporcionan una mejora de los instrumentos de las misiones Landsat anteriores, debido a la incorporación de dos nuevas bandas espectrales: un canal profundo en el azul visible (banda 1), diseñado específicamente para los recursos hídricos e investigación en zonas costeras, y un nuevo canal infrarrojo (banda 9) para la detección de nubes cirrus. Adicionalmente una nueva banda de control de calidad se incluye con cada producto de datos generado. Esto proporciona información más detallada sobre la presencia de características tales como las nubes, agua y nieve (Arizza, 2013).

Considerando que las imágenes provenientes de sensores pasivos, como LandSat (que funcionan con la radiación solar) están afectados por condiciones atmosféricas, volviéndose necesaria la reducción de estas perturbaciones, usualmente con software de tratamiento de datos espaciales en su mayoría privativos, elevando los costes para este tipo de proyectos y de difícil acceso, el mantener un estándar en el pre-procesamiento de imágenes satelitales, conocidas como correcciones radiométricas (específicamente atmosféricas), por lo que el desarrollo de modelos (algoritmos) que se ejecuten en ambientes de software de uso libre o fuente libre, sería una alternativa de trabajo en el estudio o procesamiento de datos espaciales, 
sin tener que destinar grandes sumas de dinero para compra de software especializados (Olaya,2012).

Las perturbaciones más comunes son las derivadas por dispersión atmosférica, es decir el efecto por el cual la radiación electromagnética es reflejada por gases o partículas suspendidas en la atmósfera, afectando la radiación directa e incrementando la radiación difusa. Según Jensen (1996) y Chuvieco (2002) existen tres tipos fundamentales de dispersión:

- Dispersión de Mie, esta se presenta cuando la longitud de onda es del mismo tamaño de la magnitud de las partículas (polvo y aerosoles) que la dispersan, por ejemplo gotas de agua en la atmósfera.

- La Dispersión de Rayleigh, se presenta cuando la longitud de onda es mucho mayor que el tamaño de las partículas responsables de la dispersión. Afectando las longitudes de onda más cortas (humo o bruma).

- Dispersión No Selectiva, ocurre cuando la longitud de onda es mucho menor que las partículas atmosféricas en suspensión (vapor de agua, niebla o nubes).

Siendo la corrección atmosférica por reducción de dispersión de Rayleigh, uno de los métodos más aplicados para calcular la reflectancia sin perturbaciones como alternativa a los métodos radiométricos con firmas espectrales, es primordial su aplicación utilizando algoritmos que puedan correr en un software libre, y poder corregir la dispersión molecular que se produce por partículas atmosféricas mucho más pequeñas en tamaño que la longitud de onda de la radiación electromagnética (Chuvieco, 2002, APN-SIB, 2005).

Ahora bien, si observamos la estructura de los Sistemas de Información Geográfica (SIG) en general se manejan en base a dos modelos de datos uno vectorial y otro ráster, este último tiene que ver con las imágenes digitales, las cuales se pueden definir como un arreglo matricial de filas y columnas con unidades mínimas cartografiables, denominadas celdas o pixeles. El concepto de celda en una malla ráster es equivalente al de pixel, en el campo de las imágenes digitales, pero con la diferencia que representan una porción de terreno dentro de un sistema de coordenadas específico. Una particularidad más de las imágenes digitales es la composición por bandas espectrales, y cada valor recogido indican la reflectancia por unidad de longitud de onda, dependiendo de cómo se encuentre diseñado el sensor, así la imagen tendrá un número de bandas o capas (Olaya, 2012). 
Los SIG, si los vemos al cabo del tiempo con respecto a sus avances en Tecnología, Datos, y Técnicas, se encuentran ubicados desde la década de los años 50's hasta nuestros días (Figura 2).

El software tradicional se distribuye con licencias restrictivas que no permiten que el usuario emplee este de todas las formas posibles y saque de él el mayor provecho. El usuario no es libre para utilizar el programa, y se encuentra privado de ciertas libertades, por lo que estos se conocen como "software privativo" (Olaya, 2012).

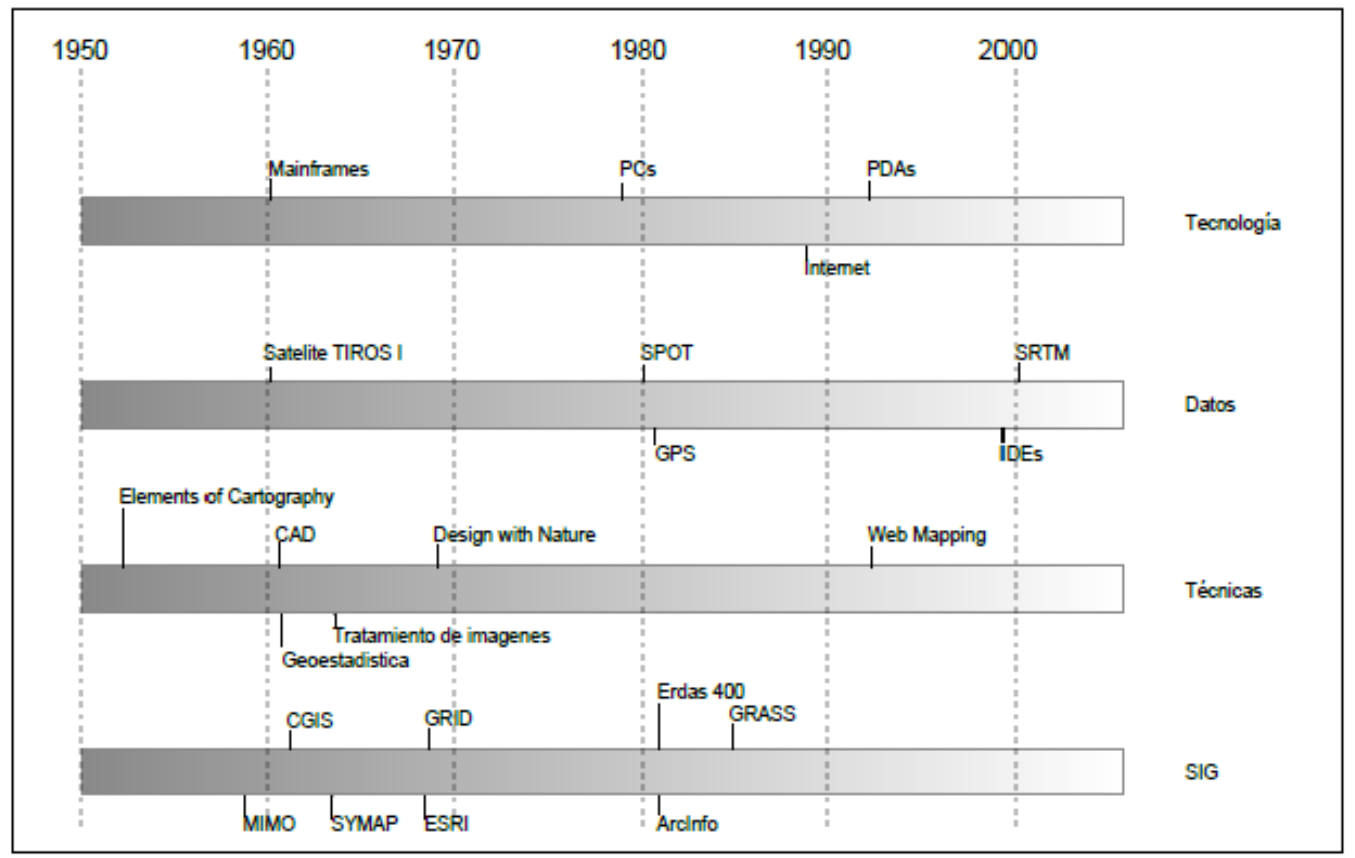

Figura 2. Evolución de los SIG (Olaya, 2012).

Por el contrario, existen otros tipos de software denominados "software libre", que se distribuyen con las siguientes libertades: i) Ejecutar el programa con cualquier propósito, ii) Estudiar cómo funciona el programa y adaptarlo a sus necesidades, iii) Distribuir copias, de forma gratuita o no gratuita, y iv) Mejorar el programa y hacer públicas las mejoras a los demás (Olaya, 2012).

Bajo este enfoque el principal objetivo fue el desarrollo de modelos para tratamiento digital de imágenes de los sensores LandSat (Evolución de 1982-2013), de la Región Central de Honduras, utilizando lenguaje de programación bajo la extensión SEXTANTE, en la plataforma del software libre gvSIG. 


\section{METODOLOGIA}

La investigación se centró en el desarrollo de un modelo a partir de las fórmulas utilizadas en los ambientes técnicos científicos de Percepción Remota, específicamente en las áreas de Tratamiento Digital de Imágenes Satelitales para el cálculo de correcciones radiométricas. La metodología aplicada en la investigación comprendió tres etapas básicas: 1) Revisión bibliográfica; 2) Crear el Modelo de Reflectancia a Tope de Atmósfera con Corrección Angular y 3) Validación de resultados.

La muestra estuvo constituida por la imagen Land Sat OLI 8 escena P18R50, que corresponde a la Región Central de Honduras. La variable a investigar fue el sensor OLI, (Tabla 1).

Tabla 1. Categorización de variables de modelización de magnitudes físicas.

\begin{tabular}{|c|c|c|}
\hline VARIABLES & DEFINICIÓN CONCEPTUAL & DEFINICIÓN OPERACIONAL \\
\hline $\begin{array}{c}\text { Reflectancia } \\
\text { Espectral }\end{array}$ & $\begin{array}{l}\text { Porcentaje de radiación incidente que } \\
\text { es reflejada por una superficie } \\
\text { bidimensional (Chuvieco, 2002). }\end{array}$ & $\begin{array}{l}\text { Sensor multiespectral, que se } \\
\text { diferencia de los sensores TM } \\
\text { y ETM+, porque posee dos } \\
\text { nuevas bandas espectrales, } \\
\text { una en el espectro visible y } \\
\text { otra en el infrarrojo. } \\
\text { Resolución de las bandas del } \\
\text { sensor OLI de LandSat } 8 \text { : } \\
\text { - Espacial: } 30 \mathrm{~m} \\
\text { - Espectral: } 9 \text { bandas } \\
\text { - Radiométrica: } 12 \text { bits } \\
\text { - Angular: Cenital } \\
\text { - Temporal: } 16 \text { dias }\end{array}$ \\
\hline
\end{tabular}

El Diseño metodológico implico la programación del algoritmo que calcula a través dela imagen con valores de ND, una imagen de Reflectancia a Tope de Atmosfera, misma que es utilizada para el cálculo con corrección por ángulo solar, como método alterno a la corrección por radiancia Rayleigh. En la Figura 3, se presentan las bases teóricas de las magnitudes físicas del desplazamiento de la energía y su interacción con los cuerpos que generan una respuesta con características sensibles a los rangos del espectro electromagnético en el dominio del rango visible (VIS) a los infrarrojos cercanos (NIR) a lejanos o térmicos (TIR). 
Además, la utilización del modelo para el cálculo de reflectancia de imágenes del sensor OLI de LandSat 8, en una investigación de tesis (Sosa, 2015), de la de Maestría en Ordenamiento y Gestión del Territorio, la cual tenía por objetivo, clasificar imágenes (LandSat ETM y OLI) por coberturas y uso del suelo, para el análisis de dinámica de cambio en una subcuenca hidrográfica, sujeta a manejo integrado. Por lo que era importante que las imágenes se manejaran a nivel de parámetros físicos (reflectancia), para que las condiciones estuvieran estandarizadas, por lo que fue aplicado el Modelo de Cálculo de Reflectancia para imágenes OLI, en la plataforma del Software Libre gvGIS, estableciéndose como la validación del algoritmo creado, específicamente para imágenes del sensor OLI.
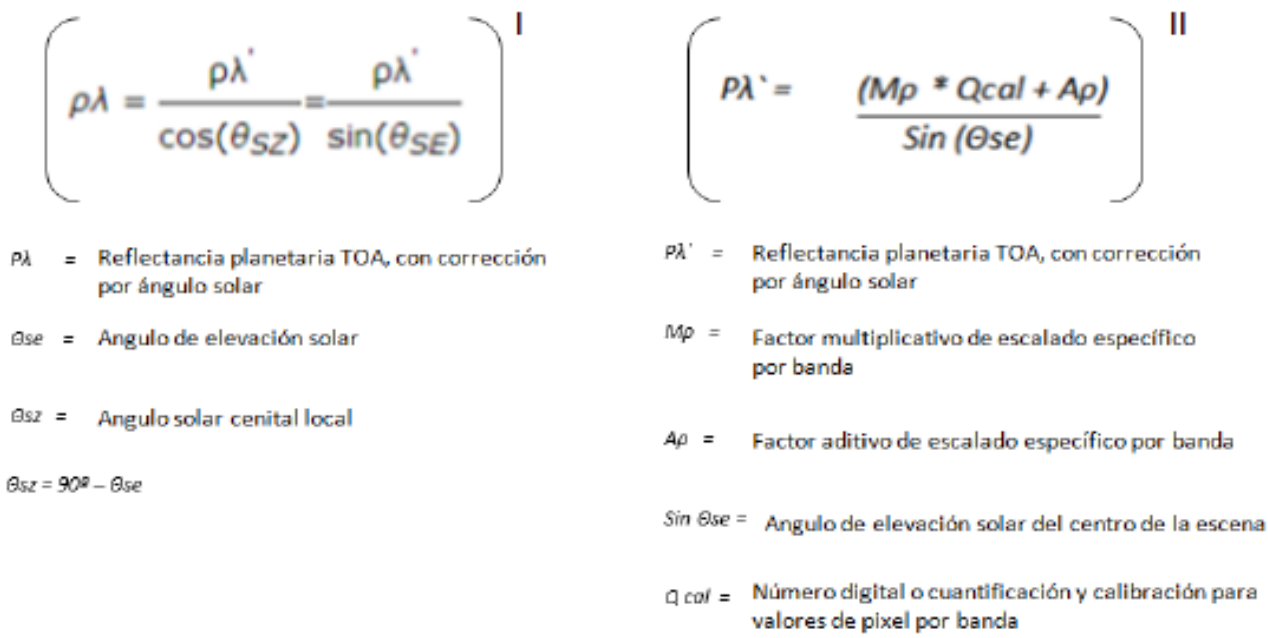

Figura 3. (I) Ecuación de conversión a reflectancia TOA con corrección angular, (II) Ecuación derivada para LandSat OLI (Modificado de IGAC, 2013).

\section{RESULTADOS}

Cada una de las bandas de la imagen fueron sometidas a un proceso de corrección radiométrica para transformar los niveles digitales (ND) a parámetros físicos de reflectancia a tope de atmósfera, con la generación de los algoritmos de radiancia, Reflectancia a Tope de Atmosfera y Reflectancia por corrección angular solar. 


\section{Reflectancia por Corrección Angular}

Los elementos para el cálculo de la reflectancia TOA por corrección angular solar son: por un lado el Factor Multiplicador de escalado específico por Banda, el cual definimos como MRB y Factor Aditivo de escalado específico por banda, definido como ARB y el ángulo de elevación solar del centro de la imagen, datos que se extraen del archivo de metadatos de la imagen en cuestión. A continuación se muestra el dialogo (Script) modelado en SEXTANTE, (Figura 4).

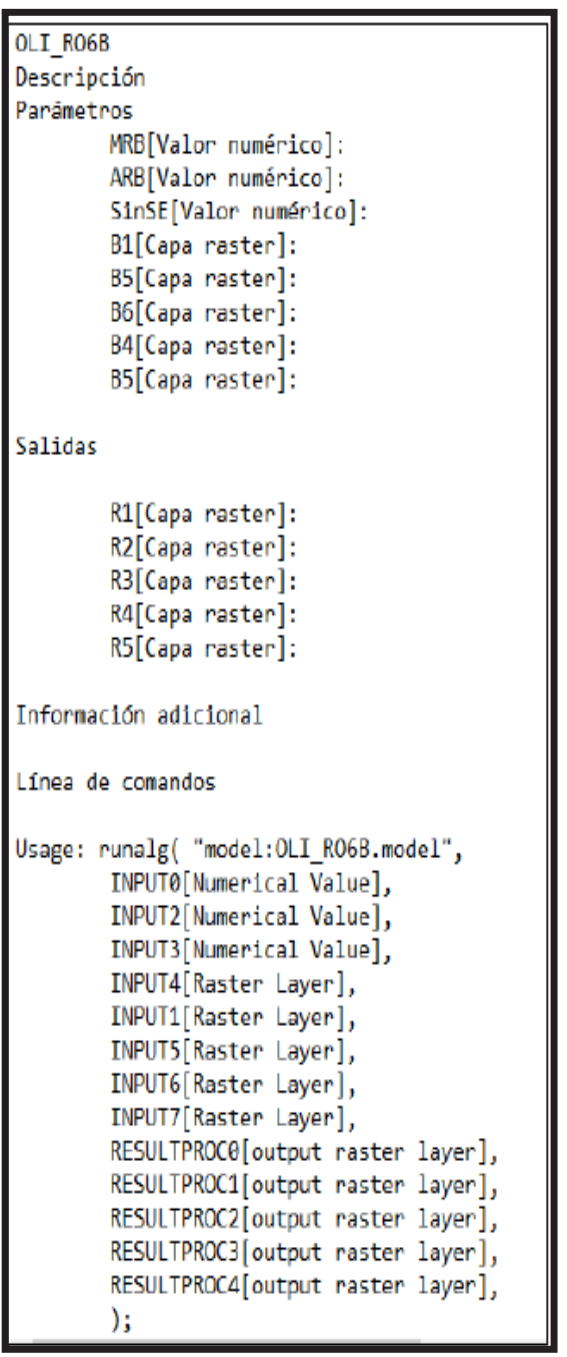

Figura 4. Script del Modelo en SEXTANTE a través del software libre gvSIG. 
En el componente de Modelizador se construyó la arquitectura que da respuesta a la ecuación de conversión a reflectancia TOA con corrección angular, introduciendo como Valores Numéricos, las bandas espectrales de la imagen como Capas Raster, tanto de las imágenes de entrada como de imágenes de salida y enlazadas por una Calculadora Raster por cada imagen y parámetro, la que ejecuta la solución, como se muestra en la Figura 5 y 6.



Figura 5. Modelizador de SEXTANTE en gvSIG.

OLI_RO6B

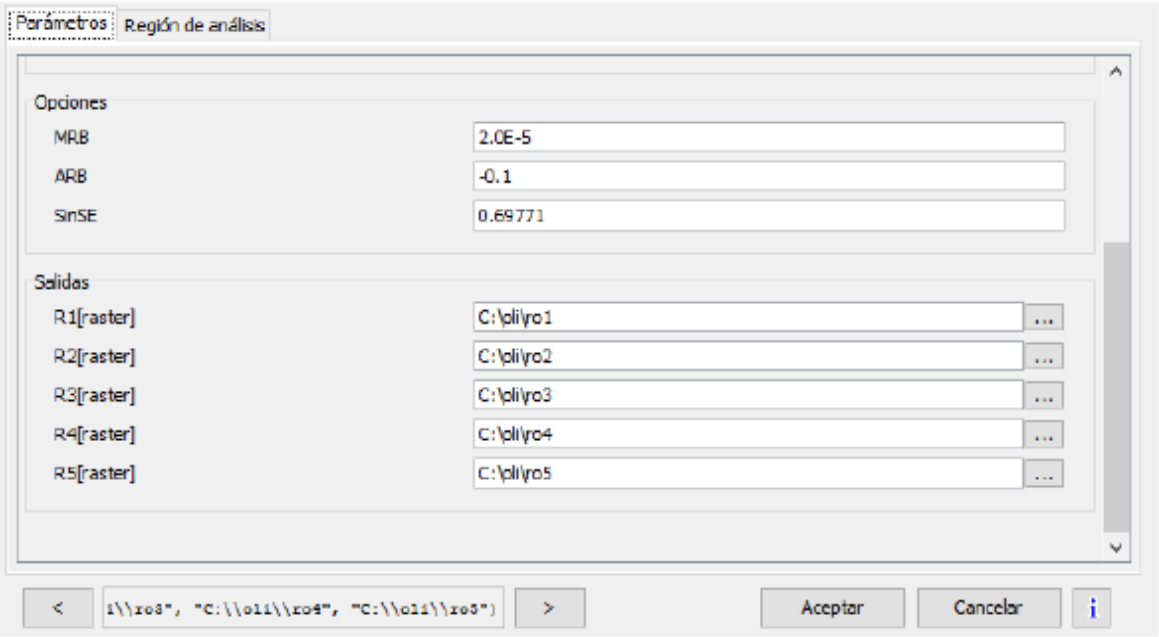

Figura 6. Cajetín de diálogos para la introducción de los parámetros necesarios en el cálculo del modelo. 
Como resultado, tenemos la arquitectura completa del modelo que calcula la radiometría antes mencionada, misma que se presenta para las bandas espectrales B2, B3, B4, B5 y B7, correspondientes a los espectros del rango del visible (Rojo, Verde y Azul) y al infrarrojo cercano e infrarrojo medio (IRC e IRM), considerando que en el sensor OLI la Banda 1, corresponde a sensibilidad de aerosoles atmosféricos, (Figura 7).

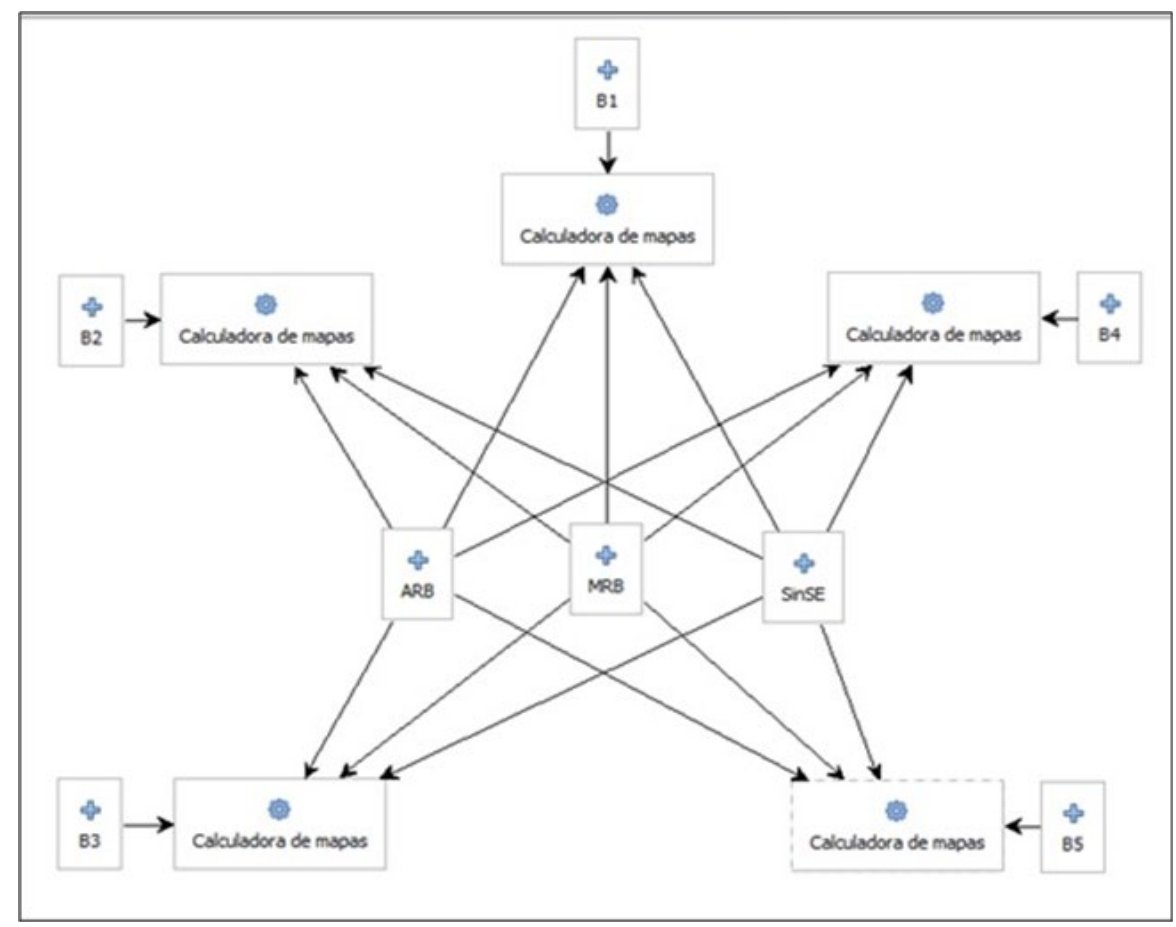

Figura 7. Diseño del modelo de reflectancia TOA con corrección angular (elaboración propia).

Los datos correspondientes a los metadatos, es el archivo que documenta los datos, en este caso se trata de las características de las diferentes resoluciones propias del sensor, así como de la información de correcciones radiométricas y geométricas, y datos orbitales respecto a la Tierra y el Sol y la inclinación angular con el sensor (Figura 8). 


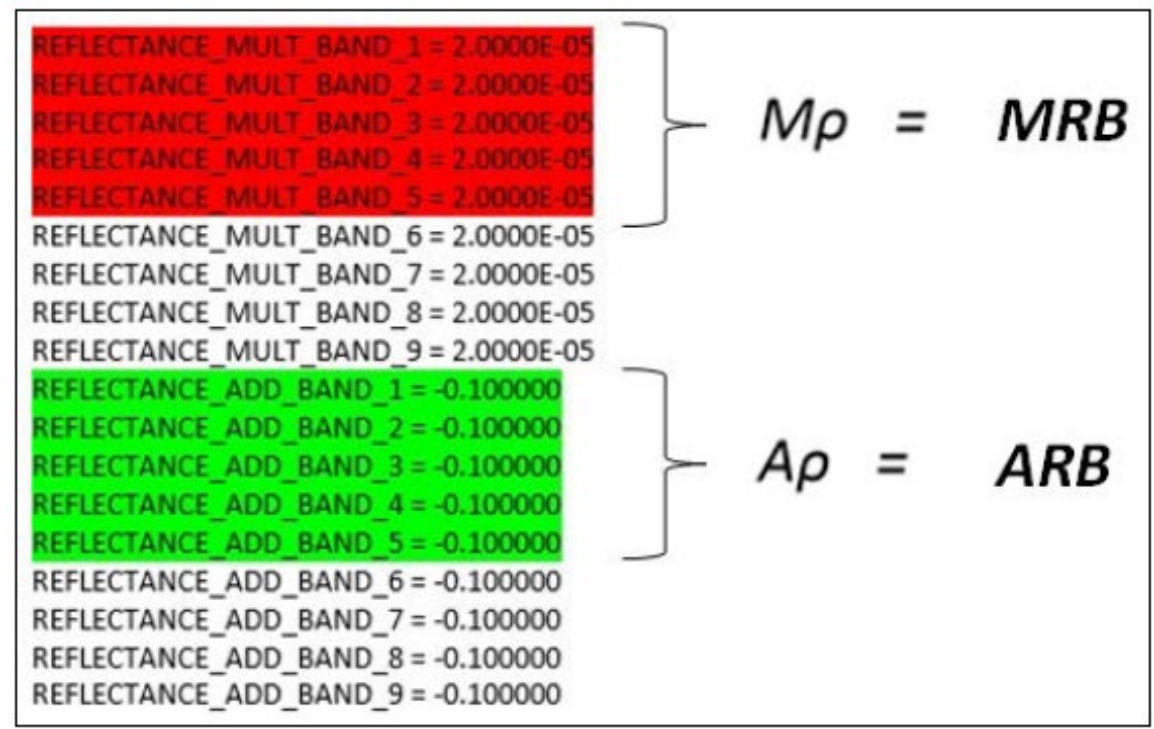

Figura 8. Corte del archivo de metadato, resaltando en color rojo el factor multiplicador de escalado especifico por banda y en resaltando en color verde el factor aditivo de escalado específico por banda, correspondiente a la imagen sujeta a cálculo.

\section{Validación del modelo}

La validación del modelo creado en el modelizador de SEXTANTE en el Software de uso libre gvGIS, se comprobó a través de la incorporación del modelo en la investigación de tesis en el posgrado de Maestría en Ordenamiento y Gestión del Territorio de la Facultad de Ciencias Espaciales, realizada por Sosa (2015) bajo el tema: Análisis Multitemporal de la Cobertura de la Tierra de la Subcuenca del Río Mocal, Lempira, Honduras, durante el Período de los años 1988 al 2014; dicho modelo fue instalado en la librería de gvSIG del ordenador en uso para la investigación de tesis (Figura 9), permitiendo utilizar los parámetros de metadato de la imagen (Tabla 2), como las variables para el cálculo de la reflectancia en la imagen del sensor LandSat 8 (OLI), correspondiente al año 2014, el resultado fue satisfactorio y permitió continuar con los objetivos de la investigación una vez estandarizadas las imágenes de los diferentes sensores (ETM y OLI). 


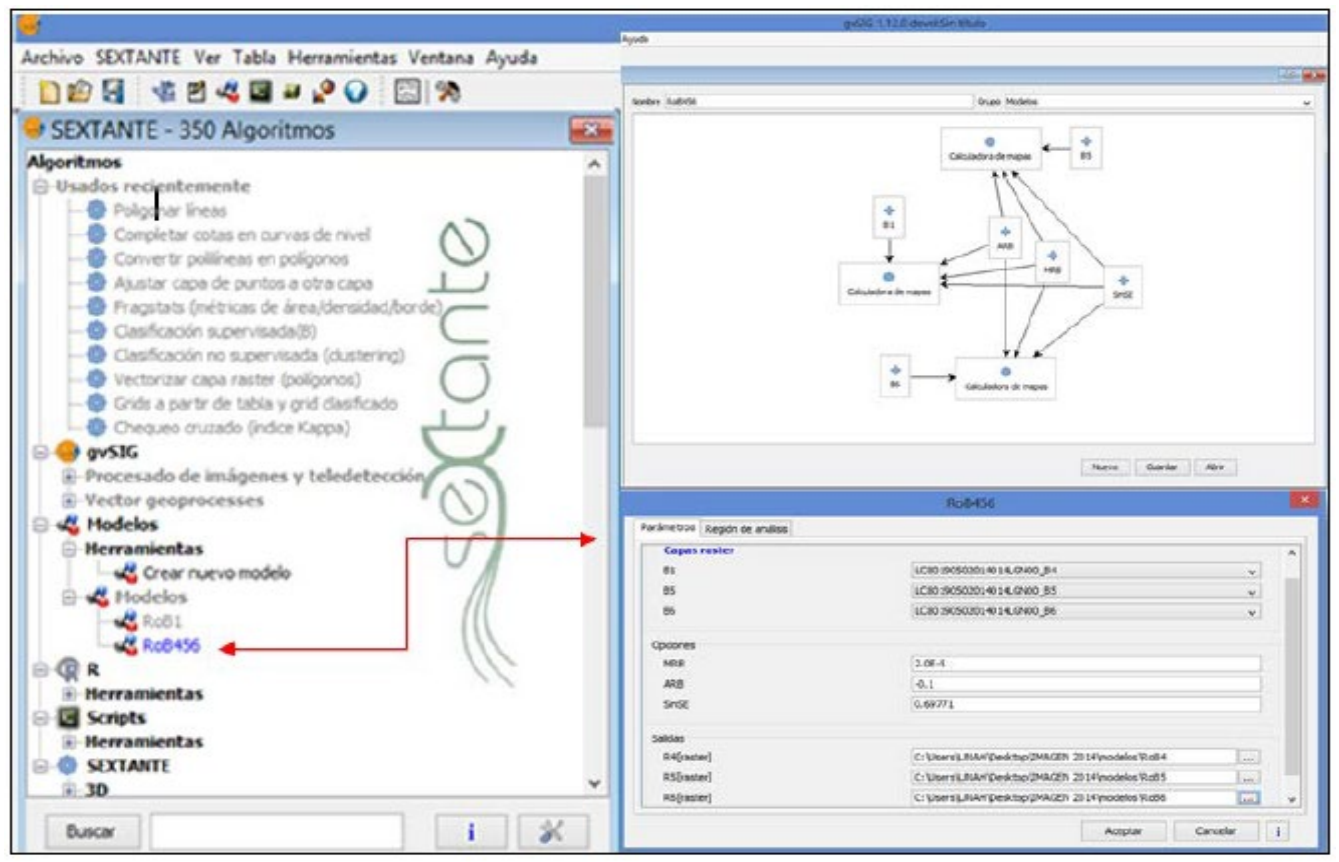

Figura 9. Modelo del cálculo de reflectancia a topo de atmosfera para imágenes LandSat 8 (Modificado de Sosa 2015).

Tabla 2. Variables para el Modelo de Cálculo de Reflectancia, según Metadatos de Imagen p19r50 del 14 de enero de 2014, Sensor OLI (Modificado de Sosa, 2015).

\begin{tabular}{|c|c|c|c|c|c|}
\hline Bandas & Factor Multiplicativo & Factor Aditivo & Qcal Máximo & Qcal Minimo & SunElevation \\
\hline 4 & $2,00 \mathrm{E}-05$ & $-0,1$ & 65535 & 1 & \multirow{2}{*}{$45,75624693^{\circ}$} \\
\hline 5 & $2,00 \mathrm{E}-05$ & $-0,1$ & 65535 & 1 & \\
\hline 6 & $2,00 \mathrm{E}-05$ & $-0,1$ & 65535 & 1 & \\
\hline
\end{tabular}




\section{DISCUSIÓN}

En su mayoría, los software para tratamiento digital de imágenes satelitales, que se utilizan en Percepción Remota son privativos, lo que vuelve de difícil acceso, el mantener un estándar en el pre-procesamiento de imágenes satelitales, conocidas como correcciones radiométricas (específicamente atmosféricas), por lo que el desarrollo de modelos (algoritmos) que se ejecutan en ambientes de software de uso libre o fuente libre, se convierte en la alternativa de trabajo para los laboratorios o centros de investigación que se dedican al estudio o procesamiento de datos espaciales, sin tener que destinar grandes sumas de dinero para compra de software especializados.

Autores como Maia, L. H., Loar dos Santos Coutinho, Gustavo Mota de Sousa, Mauro Antonio HomemAntunes (2015), concluyen que la corrección atmosférica es un procedimiento necesario para el análisis de una imagen de satélite, ya que el efecto atmosférico es relevante y merece tomarse en cuenta en el procesamiento de imágenes digitales de sensores remotos, utilizadas principalmente para estudios de ocupación del suelo en diferentes momentos (dinámica de cambios) o en la preparación de índices espectral. Además, consideran que los resultados mostrados en su estudio en donde aplican el modelo denominado AtmCor4OLI, que corre en el Software Privativo ENVI, fue eficiente y capaz de realizar un trabajo satisfactorio de corrección atmosférica de imagenes OLI/LandSat 8, esencial para la difusión de información científica y tecnológica.

\section{CONCLUSIONES}

Se obtuvo un modelo (algoritmo) a partir de fórmulas utilizadas en ambiente técnico científicos de Percepción Remota, que funciono satisfactoriamente en el software libre.

En el cálculo de imágenes de reflectancia con corrección angular, el modelo desarrollado proporciona resultados válidos, además de simplificar los procedimientos al obtener la imagen en parámetros físicos de reflectancia con corrección angular a partir de los valores digitales de la imagen (ND).

\section{BIBLIOGRAFIA}

- $\quad$ APN-SIB. 2005. Protocolo para el pre-procesamiento de imágenes satelitales LandSat para aplicaciones de la Administración de Parques Nacionales. http:// www.sib.gov.ar/archivos/Protocolo_Landsat.pdf abril, 2013. 
- Arizza, A. 2013. Descripción y Corrección de Productos LandSat 8 LDCM (LandSat Data ContinuityMission) Versión 1.0.Centro de Investigación y Desarrollo en Información Geográfica (CIAF), Instituto Geográfico Agustín Codazzi (IGAC), Colombia. http://www.un-spider.org/sites/default/files/ LDCM-L8.R1.pdf.

- Chuvieco, E. 2002. Teledetección Ambiental. La Observación de la Tierra desde el Espacio. Editorial Ariel, Barcelona, España. 586 pp.

- Corrales Andino, R. E. 2010. Caracterización de alternación hidrotermal y dinámica de cobertura del suelo mediante métodos de teledetección, en el Valle de Choluteca, Honduras. Tesis de Maestría, UNAH. Tegucigalpa. 113 pp

- Hernández Cobarrubias, A. M. y García Solís, D.E.. 2014.Análisis de cambio en la cobertura espacial del manglar en el área de protección de flora y fauna Laguna de Términos. Facultad de Ingenieria, UNAM. Disponible en: http://www. ptolomeo.unam.mx:8080/xmlui/bitstream/handle/132.248.52.100/4379/Tesis. pdf? sequence $=1$.

- IGAC. 2013. Descripción y Corrección de Productos LandSat 8. LDCM. Bogotá, Colombia. Consultado en: www.igac.gov.co - ciaf@igac.gov.co. 15 de Julio de 2015.

- INEGI. s.a. Aspectos Técnicos de las Imágenes LandSat. Dirección General de Geografía y Medio Ambiente, México. http://www.inegi.org.mx/geo/contenidos/ imgpercepcion/imgsatelite/doc/aspectos_tecnicos_imagenes_ladsat.pdf. 17 de febrero de 2015.

- Jensen, J.R. 1996. Introductory Digital Image Processing.A Remote Sensing Perspective. 2da Edición. Prentice Hall. New Jersey. 110-113 pp.

- HersMaia, L., Dos Santos Coutinho, L., Mota de Sousa, G.,yHomemAntunes, M.A. 2015. Obtenção da reflectância da superfície para imagens OLI do Landsat 8 comum modelo de transferênciaradiativa. Anais XVII Simpósio Brasileiro de Sensoriamento Remoto - SBSR, João Pessoa-PB, Brasil, 25 a 29 de abril de 2015, INPE. 2992-2996 pp.

- Olaya, V. 2012. Sistemas de Información Geográfica. www.creativecommons. org.http://wiki.osgeo.org/wiki/Libro_SIG. 12 de septiembre de 2014. 
- Sosa Reyes, Y. 2015. Análisis Multitemporal de la Cobertura de la Tierra de la Sub cuenca del Río Mocal, Lempira, Honduras, durante el periodo de los años 1988 al 2014. Tesis de Maestría, Universidad Nacional Autónoma de Honduras, Tegucigalpa, Honduras. 